\title{
Relationship between Friction Coefficient and Contact Angle on Metal Plate in Mixed Solution of Polyethylene Glycol and Ethylene Glycol
}

\author{
Kazuaki Hachiya ${ }^{*}$ \\ Department of Mechanical System Engineering, Okayama University of Science \\ 1-1 Ridai-cho, Kita-ku, Okayama 700-0005, Japan \\ *Corresponding author: hachiya@mech.ous.ac.jp \\ ( Manuscript received 28 October 2015; accepted 07 February 2016; published 30 April 2016 ) \\ ( Presented at the International Tribology Conference Tokyo 2015, 16-20 September, 2015)
}

\begin{abstract}
Interaction between thickener such as polyethylene glycol (PEG) and glycol antifreeze such as ethylene glycol (EG) was investigated by measuring the friction coefficient and the contact angle of the mixed solution of polyethylene glycol and ethylene glycol. The friction coefficient of undiluted EG was larger than that of undiluted polyethylene glycol with molecular weight 400 (PEG400), and the friction coefficient in the mixed solution of PEG400 and EG was expected to increase with an increase in the content of EG added to the mixed solution. However, the friction coefficient of the mixed solution at a sliding speed of $0.05 \mathrm{~m} / \mathrm{s}$ showed the maximum value at EG content 70 mass\%. The contact angle of the mixed solution of PEG400 and EG at $40^{\circ} \mathrm{C}$ increased with an increase in the EG content in the lubricant on the unheat-treated metal plate, but showed the maximum value at EG content $60 \mathrm{mass} \%$ on the metal plate which was heat-treated for $10 \mathrm{~min}$ at $190^{\circ} \mathrm{C}$ and then was cooled at room temperature. The agreement of both the EG content dependences of the friction coefficient and the contact angle might be explained by the intermolecular interaction between PEG400 and EG molecules which was induced on the metal oxide surface.
\end{abstract}

Keywords: friction coefficient, contact angle, mixed solution, polyethylene glycol, ethylene glycol

\section{Introduction}

The water-glycol hydraulic fluid was consisted of the thickener such as ethylene glycol, the glycol antifreeze such as ethylene glycol, and water. The kinematic viscosity was controlled by the thickener, and the degradation of the lubricant caused by the decrease in the lubricant viscosity has been evaluated by the ASTM ultrasonic shear stability test by using the continuous ultrasonic irradiation method with the sonic oscillator operated at $10 \mathrm{kHz}$ [1-3]. However, the friction coefficient of PEG did not change by the cleavage of the principal chain of the thickener molecules by using the ultrasonic processor, or was not influenced by the change in the molecular weight of PEG [4]. The similar molecular weight dependence of the constant friction coefficient was also observed by the diol compounds of polypropylene glycols (PPG) [5]. The sliding metal surface of the tribometer was changed into the metal oxide surface by a strong mechanical shearing force $[1,2,6]$ and heat. Since the metal oxide surface was chemically reactive, and various substances were adsorbed on the metal oxide surface [7,8]. PEG and PPG molecules were also adsorbed on the metal oxide sliding surface, and then the friction coefficients of the lubricants were kept almost constant by the protective film formation $[4,5]$. The protective film formation of PEG and PPG on the metal oxide surface was investigated by the contact angle measurement. Although PPG was more hydrophobic than PEG, the contact angle of PPG was smaller than that of PEG on the hydrophilic metal oxide surface [9]. The order of the contact angles between PEG and PPG indicates that the adjacent PEG or PPG molecules inside the drop were connected by hydrogen bonding with -OH groups on the both ends of the molecules [9]. The purpose of this paper is to clarify the interaction between thickener such as PEG and glycol antifreeze such as EG which were contained in water-glycol hydraulic fluid.

\section{Experimental methods}

The Ethylene glycol and polyethylene glycol with the average molecular weight of 400 (Wako Pure Chemical Industries, Ltd.) were used without further purifications and were abbreviated as EG and PEG400, respectively. The properties of molecular weights, kinematic viscosities and water contents of PEG400 and EG were shown in Table 1. The friction coefficient in the lubricant 
Table 1 Properties of tested lubricants

\begin{tabular}{|l|c|c|}
\hline Lubricant & PEG400 & EG \\
\hline $\begin{array}{l}\text { Average molecular weight } \\
\text { Molecular weight }\end{array}$ & $\begin{array}{c}400^{\mathrm{a}} \\
(360-440)\end{array}$ & $62.07^{\mathrm{b}}$ \\
\hline $\begin{array}{l}\text { Kinematic viscosity at } 40^{\circ} \mathrm{C}, \\
\mathrm{mm}^{2} / \mathrm{s}\end{array}$ & 33.1 & 7.4 \\
\hline $\begin{array}{l}\text { Water content, } \\
\text { mass\% }\end{array}$ & 0.29 & 0.52 \\
\hline
\end{tabular}

was measured by using a ball-on-disk arrangement on a CSM High Temperature Tribometer. A bearing steel ball (JIS SUJ2) of $6 \mathrm{~mm}$ diameter was installed at the bottom at the ball holder, and a $50 \mathrm{~mm}$ diameter stainless steel petri dish (JIS SUS304, AS ONE Corporation) $15 \mathrm{~mm}$ high and $0.6 \mathrm{~mm}$ thick was placed in the sample holder. The arithmetic average roughness and the maximum height roughness of the stainless steel petri dish were 0.14 and $1.21 \mu \mathrm{m}$, respectively. $2 \mathrm{~g}$ of the lubricant was added in the petri dish at 20,40 and $60^{\circ} \mathrm{C}(293,313$ and $333 \mathrm{~K})$. The running-in was done in the stainless petri dish containing the lubricant for $30 \mathrm{~min}$ at a sliding speed of $0.005 \mathrm{~m} / \mathrm{s}$ and a constant load of $1 \mathrm{~N}$ (i. e., $0.44 \mathrm{GPa}$ ). The mean values of the friction coefficients were measured for $30 \mathrm{~min}$ at the constant load of $1 \mathrm{~N}$ and the sliding speeds from 0.001 to $0.15 \mathrm{~m} / \mathrm{s}$.

A metal plate tested for the contact angle measurement was a commercial product of a rolled stainless steel plate (JIS SUS304), which was $50 \mathrm{~mm}$ in length and width, and $1 \mathrm{~mm}$ in thickness. The arithmetic average roughness and the maximum height roughness were 0.14 and $1.21 \mu \mathrm{m}$, respectively. Prior to measure the contact angle, the metal plate was unheated or was heat treated for $10 \mathrm{~min}$ at $150-230^{\circ} \mathrm{C}$, and was thereafter cooled at room temperature. The drop shape method was applied to measure the contact angles of undiluted EG, PEG400, and the mixed solution of EG and PEG400 on the stainless steel plate on the hot plate at $40^{\circ} \mathrm{C}[10,11]$. Because the receding angle became zero by the adsorption of PEG molecules on the metal oxide surface, the contact angle of the lubricant on the metal oxide surface was represented only by the advancing angle.

The adiabatic compressibility $\beta$ in the lubricant was obtained by using the density $\rho$ and the ultrasonic velocity $u$ as the following formula [12]:

$$
\beta=\frac{1}{\rho u^{2}}
$$

The ultrasonic velocity in the lubricant at $40^{\circ} \mathrm{C}$ was measured by using the pulse-echo technique described by McClements and Povey [5,13,14].

Glycol and poly glycols have generally moisture-absorbency in high humidity atmospheric conditions, and then water contents of PEG400 and EG were checked before the measurements of the friction coefficients and the contact angles. Since PEG400 and EG on the metal plate vaporized at high temperature, water contents in PEG400 and EG were obtained by the measurements of the mass reductions of lubricants in the stainless petri dishes which were heated at 100 and $60^{\circ} \mathrm{C}$ for 30 minutes, respectively. After EG in the stainless petri dish was heated at $70-100^{\circ} \mathrm{C}$ for 30 minutes, it was cooled to the room temperature in the desiccator. However, very small droplets of EG were attached to the inner wall of the desiccator owing to the vaporization of EG. The heating temperature of EG on the hot plate was decided to adopt $60^{\circ} \mathrm{C}$.

The friction coefficients and contact angles were measured at $40^{\circ} \mathrm{C}$, at which the ASTM ultrasonic shear stability test was carried out by using the continuous ultrasonic irradiation method with the sonic oscillator operated at $10 \mathrm{kHz}$ [1-4]. 1.5 mass $\%$ of water was added to PEG400 in the stainless petri dish. At $40^{\circ} \mathrm{C}, 30$ and $40 \%$ of 1.5 mass $\%$ of the added water decreased after 1 and $2 \mathrm{~h}$, respectively. This indicates that water in PEG400 vaporized at relative humidity $60 \%$ and $40^{\circ} \mathrm{C}$. At relative humidity $60 \%$ and $20^{\circ} \mathrm{C}$, however, the weight of PEG400 increased with time in the atmosphere. The change in the water contents of PEG400 increased to become 1.6 and 3.1 mass $\%$ after 1 and $2 \mathrm{~h}$, respectively, and PEG400 absorbed water from moisture in the air at $20^{\circ} \mathrm{C}$. This indicates that the measurements of the contact angles and the friction coefficients of hygroscopic PEG400 and EG should be carried out at the temperature above $40^{\circ} \mathrm{C}$.

\section{Results and discussion}

The friction coefficients of undiluted diol compounds such as PEG400 and EG on the metal plates were influenced by the sliding speed as shown in Fig. 1. The friction coefficient of undiluted PEG400 was 0.18 at a sliding speed of $0.001 \mathrm{~m} / \mathrm{s}$ and the temperature $40^{\circ} \mathrm{C}$, but were almost constant to be 0.15 at $0.005-0.15$ $\mathrm{m} / \mathrm{s}$. The friction coefficient 0.29 of undiluted $\mathrm{EG}$ at a sliding speed of $0.001 \mathrm{~m} / \mathrm{s}$ decreased to be 0.22 at 0.01 $\mathrm{m} / \mathrm{s}$, but increased with an increase in the sliding speed. Since the friction coefficient of undiluted EG was larger than that of undiluted PEG400, the friction coefficient in the mixed solution of PEG400 and EG was expected to

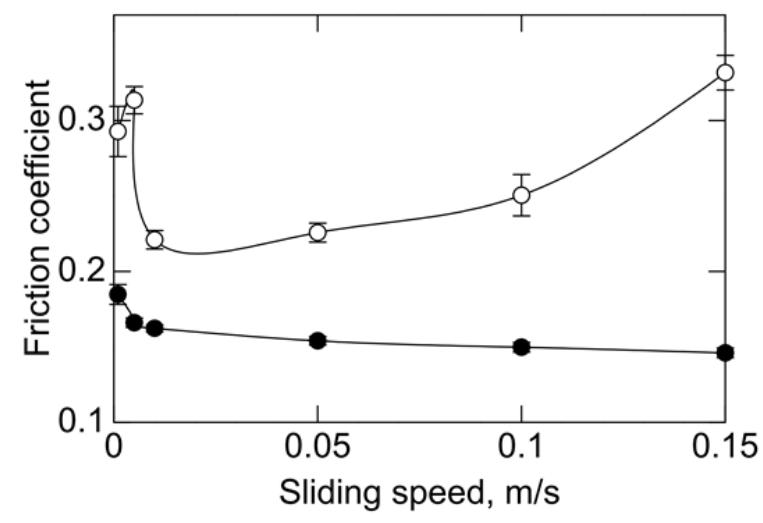

Fig. 1 Sliding speed dependence of friction coefficients of undiluted EG (O) and PEG400 (•) at a load of $1 \mathrm{~N}$ and $40^{\circ} \mathrm{C}$ 


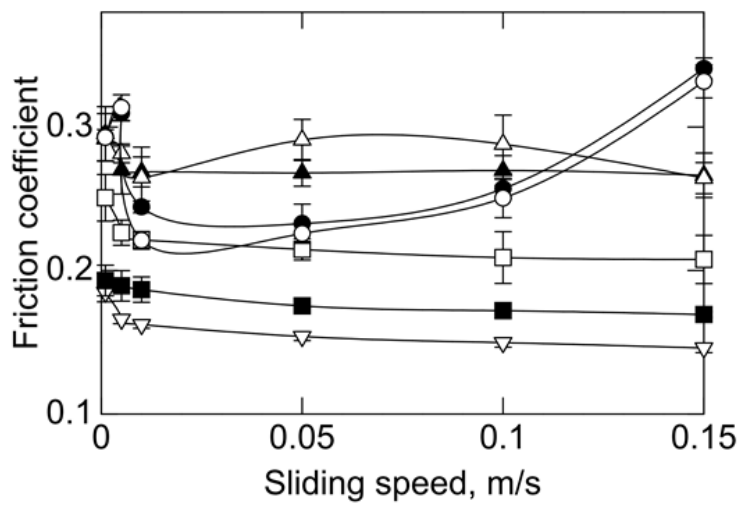

Fig. 2 Sliding speed dependence of friction coefficients of EG (100\%) (O), PEG400 $(20 \%)+$ EG $(80 \%)(\bullet)$, PEG400 (30\%) + EG $(70 \%)(\triangle)$, PEG400 (40\%) + EG $(60 \%)(\boldsymbol{\Delta})$, PEG400 $(60 \%)+$ EG $(40 \%)$ (口), PEG400 (80\%) + EG (20\%) (ロ), and PEG400 $(100 \%)(\nabla)$ at a load of $1 \mathrm{~N}$ and $40^{\circ} \mathrm{C}$

increase with an increase in the content of EG added to the mixed solution. Figure 2 shows the sliding speed dependence of friction coefficients of the mixed solution at the various EG content added to PEG400. The each friction coefficient of the mixed solution at the sliding speed range of 0.001 to $0.15 \mathrm{~m} / \mathrm{s}$ increased monotonously with increasing in the EG content from 0 to 60 mass $\%$, but showed the maximum value at EG content 70 mass $\%$ at $0.05 \mathrm{~m} / \mathrm{s}$ and moderately decreased thereafter. In order to clarify the maximum friction coefficient value at EG content 70 mass \% and sliding speed $0.05 \mathrm{~m} / \mathrm{s}$, the friction coefficient of the mixed solution at the sliding speed of $0.05 \mathrm{~m} / \mathrm{s}$ was plotted as a function of the EG content added to the mixed solution as shown in Fig. 3. In this figure, $W_{\mathrm{e}}$ and $W_{\mathrm{p}}$ denote the weights of EG and PEG, respectively, and $W_{\mathrm{e}} /\left(W_{\mathrm{p}}+\right.$ $W_{\mathrm{e}}$ ) denotes the EG content added to the mixed solution

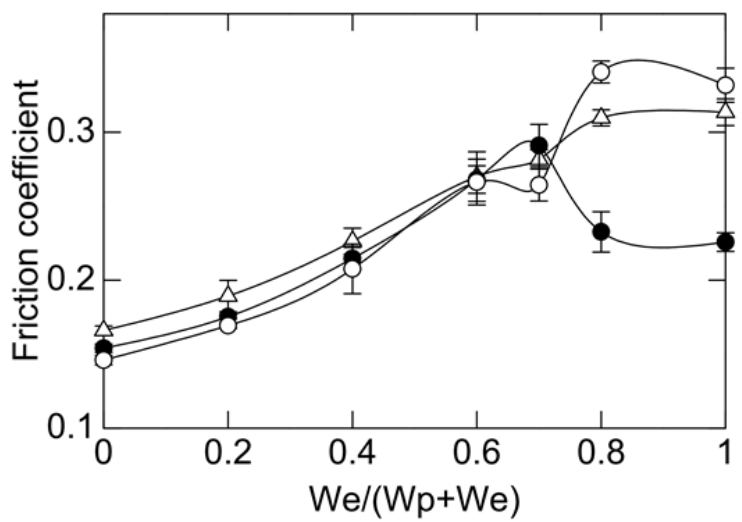

Fig. 3 Plots of friction coefficients of the mixed solutions as a function of the EG content added to the mixed solution at a load of 1 $\mathrm{N}, 40^{\circ} \mathrm{C}$ and sliding speeds of $0.005(\triangle)$, $0.05(\bullet)$ and $0.15(\circ) \mathrm{m} / \mathrm{s}$ of PEG and EG. Although the friction coefficient of the mixed solution increased with an increase in EG content at the sliding speed of 0.005 or $0.15 \mathrm{~m} / \mathrm{s}$, it showed the maximum value at EG content 70 mass \% and sliding speed $0.05 \mathrm{~m} / \mathrm{s}$.

The EG content dependence of the friction coefficient of the mixed solution in Fig. 3 was compared with that of the kinematic viscosity of the mixed solution at 20, 40 and $60^{\circ} \mathrm{C}$ as shown in Fig. 4(a), in order to investigate the cause of the maximum friction coefficient value at EG content 70 mass $\%$ and sliding speed $0.05 \mathrm{~m} / \mathrm{s}$. Because the molecular weight of EG was smaller than that of PEG400 and the kinematic viscosities of the homologous lubricants were proportional to the molecular weight of the lubricants [15], the kinematic viscosity of the mixed solution of PEG400 and EG decreased with an increase in the EG content added to the mixed solution at each temperature, but did not show the maximum value which was shown in Fig. 3. Figure $4 \mathrm{~b}$ shows the EG content dependence of the compressibility of the mixed solution at 20, 40 and $60^{\circ} \mathrm{C}$, which was calculated from Eq. (1) by using the experimental values of the ultrasonic velocity and density of the mixed solution at the same temperatures. The compressibility as well as the ultrasonic velocity and density of the mixed solution (not shown) of the mixed solution did not also show the particular
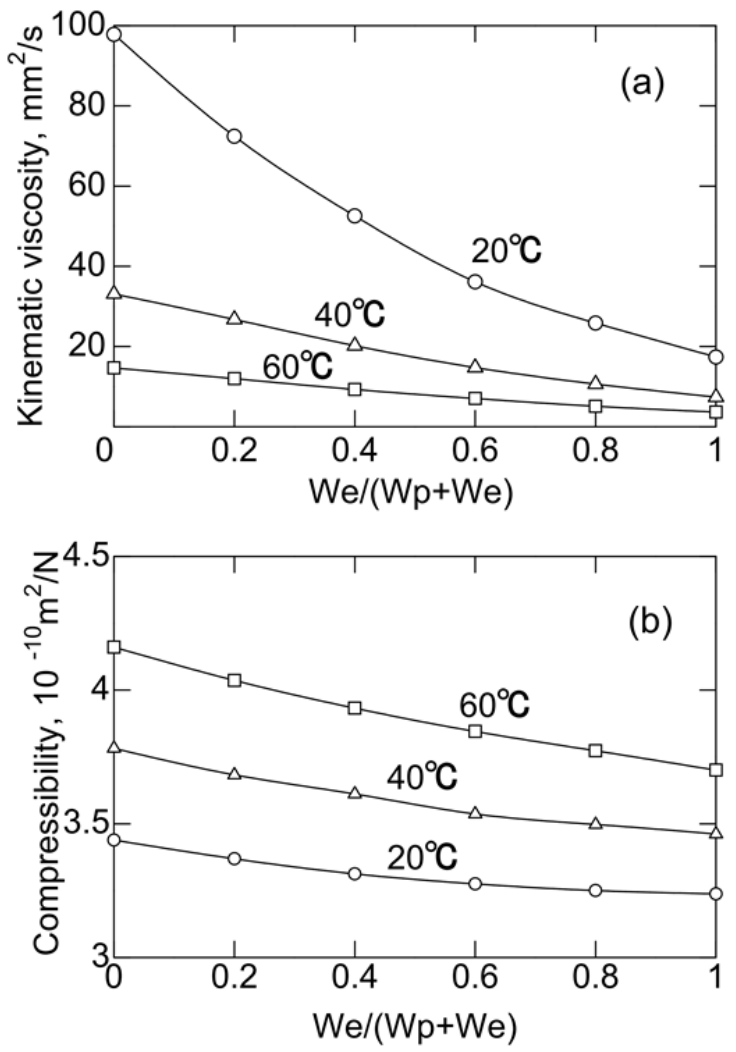

Fig. 4 Plots of (a) kinematic viscosity and (b) compressibility of the mixed solution as a function of EG content added to the mixed solution of PEG400 and EG 
maximum value at 20,40 or $60^{\circ} \mathrm{C}$.

The sliding speed dependences of the friction coefficients of the mixed solutions at EG contents of 0 , 70 and 100 mass $\%$ in Fig. 2 were measured at 20, 40 and $60^{\circ} \mathrm{C}$, and were shown in Figs. $5(\mathrm{a}-\mathrm{c})$, respectively. As seen from Figs. 5(a,c), both the friction coefficients of undiluted PEG400 (i. e. EG content 0 mass\%) and undiluted EG (i. e. EG content 100 mass\%) were not influenced by the temperatures of the lubricants. These indicate that the lubricant films formed on the metal oxide sliding surface $[5,9]$ were stable and the structural changes of the lubricant films were not caused by the temperature change from 20 to $60^{\circ} \mathrm{C}$. Figure 5 (b) shows
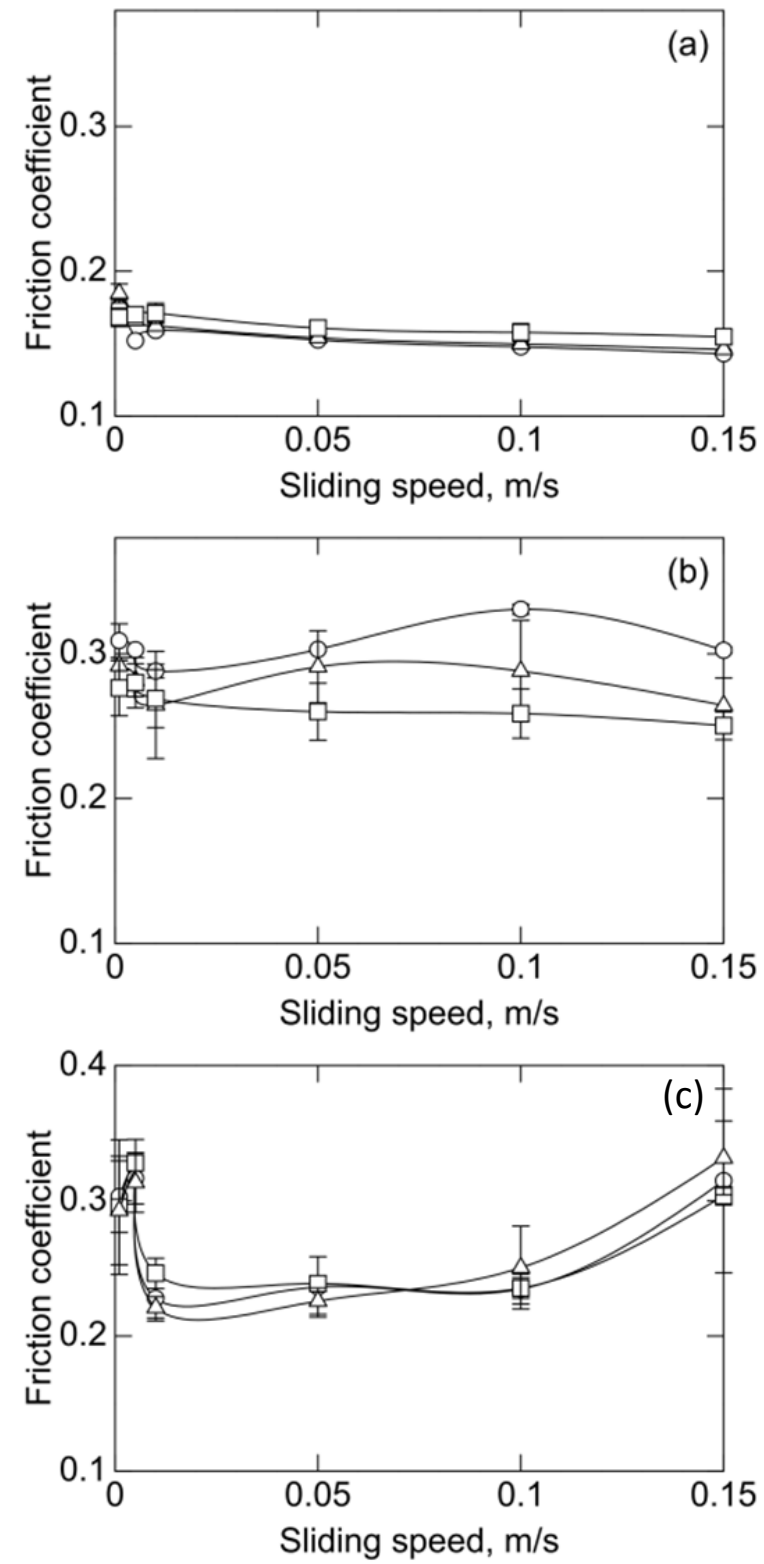

Fig. 5 Sliding speed dependences of friction coefficients of the mixed solutions at EG content (a) 0 mass $\%$, (b) 70 mass $\%$, (c) 100 mass $\%$ at $20^{\circ} \mathrm{C}(\circ), 40^{\circ} \mathrm{C}(\triangle)$, and $60^{\circ} \mathrm{C}$ (), and a load of $1 \mathrm{~N}$ the sliding speed dependences of the friction coefficients of the mixed solutions at 20,40 and $60^{\circ} \mathrm{C}$ at EG content 70 mass\%. The maximum values of the friction coefficients at 20 and $40^{\circ} \mathrm{C}$ appeared at the sliding speeds of 0.1 and $0.05 \mathrm{~m} / \mathrm{s}$, respectively. Because the maximum values of the friction coefficients occurred in the mixed solutions of PEG400 and EG, but did not occurred in the undiluted PEG400 and EG as seen from Figs. 5(a-c), the appearance of the maximum friction coefficient in Fig. 5(b) is seemed to be caused by the intermolecular interaction between the PEG400 and EG molecules. Furthermore, the maximum friction coefficient value in Fig. 5(b) decreased with increasing temperature from 20 to $60^{\circ} \mathrm{C}$. This indicates that the intermolecular interaction between PEG400 and EG molecules in Fig. 5(b) might be disturbed by the increase in the thermal motion of the lubricant molecules in the mixed solution.

The intermolecular interaction between PEG400 and EG molecules observed in the EG content dependences of the friction coefficients in Figs. 3 and 5(b) was investigated in more detail by the contact angle measurements of the mixed solutions on the heat-treated metal plates. Figure 6 shows the plots of contact angles of undiluted PEG400 and EG at $40^{\circ} \mathrm{C}$ against heat-treated temperatures of stainless steel plate for 10 min. Both the contact angles of undiluted PEG400 and EG decreased with increasing heat-treated temperature, and the contact angle of EG was larger than that of PEG400.

The molecular length of EG was shorter than that of PEG400, and then the difference between the contact angles of EG and PEG400 in Fig. 6 indicates that the intermolecular interaction such as hydrogen bonding between the adjacent EG molecules was larger than that between the adjacent PEG400 molecules [9]. Since the amount of the metal oxide film increased with increasing heat-treated temperature [6], the decrease in the contact angle of EG or PEG400 in Fig. 6 might arise

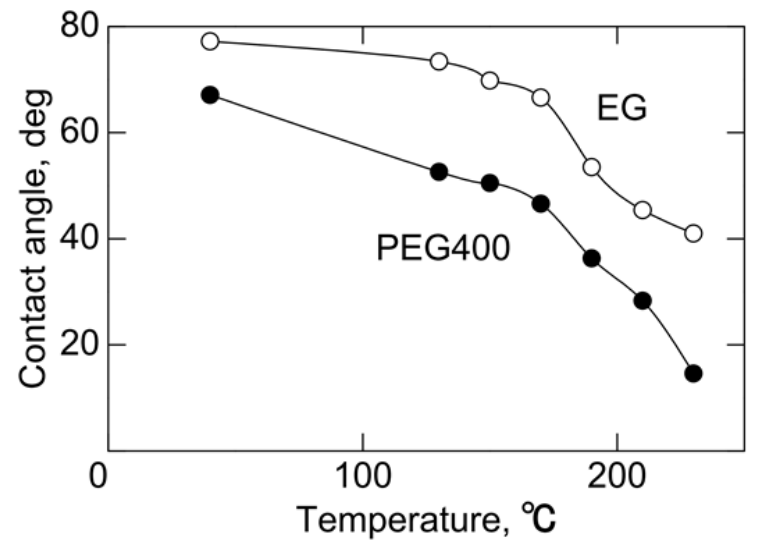

Fig. 6 Plots of contact angles of undiluted EG and PEG400 at $40^{\circ} \mathrm{C}$ against heat-treated temperature of stainless steel plate for 10 $\min$ 
from the increase in the interaction between the EG molecules and the metal oxide surface or from that between the PEG400 molecules and the metal oxide surface.

Figure 7 shows the EG content dependences of contact angles of the mixed solutions of PEG400 and EG at $40^{\circ} \mathrm{C}$ on the unheat-treated metal plate and on the metal plates which were heat-treated at 150 to $210^{\circ} \mathrm{C}$ for $10 \mathrm{~min}$ and were cooled at the room temperature. The contact angles of the mixed solutions of PEG400 and $\mathrm{EG}$ at $40^{\circ} \mathrm{C}$ in Fig. 7 increased monotonously with increasing in the EG content in the lubricants on the unheat-treated metal plate and the metal plate heat-treated at $150^{\circ} \mathrm{C}$. The contact angles of the mixed solutions on the metal plates heat-treated at 170, 190 and $210^{\circ} \mathrm{C}$, however, showed the maximum values at EG content 80,60 and 70 mass\%, respectively. Although the contact angle was controlled by the bulk phase which was formed by the interaction between the adjacent lubricant molecules [9], the maximum value of the contact angle did not appear at the lower temperatures of $40^{\circ} \mathrm{C}$ (i. e. unheat-treated temperature) and $150^{\circ} \mathrm{C}$, but occurred at the higher temperatures of 170 to $210^{\circ} \mathrm{C}$ at which the metal oxide film was produced sufficiently on the metal plate. The maximum contact angle in Fig. 7, therefore, might be resulted from the interaction between three substances of PEG400, EG molecules and the metal oxide film.

On the basis of the results observed from the contact angle measurements in Figs. $(6,7)$, the appearance of the maximum friction coefficient value in Figs. 3 and $5(\mathrm{~b})$ might be explained by the change in the lubricant film on the metal oxide, which was formed by a strong mechanical shearing force and heat on the sliding metal surface in the friction coefficient measurement. The lubricant film of the undiluted PEG400 on the metal oxide surface seems to have a regular structure, because the friction coefficient of PEG400 did not show the

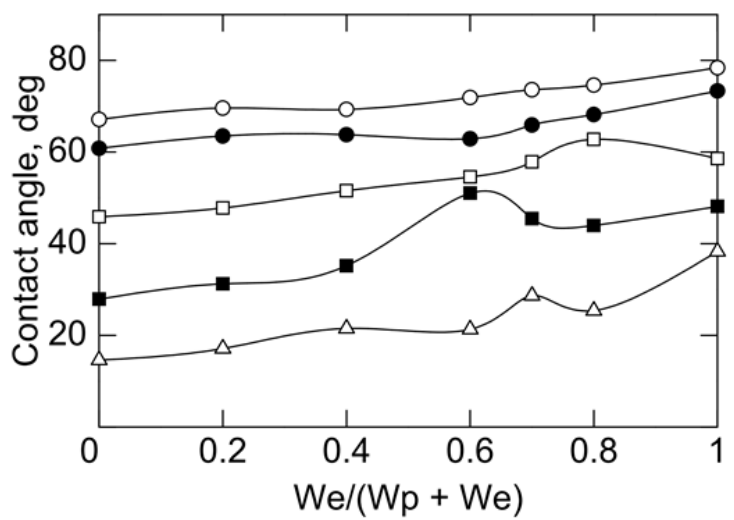

Fig. 7 EG content dependence of contact angle of the mixed solution of PEG400 and EG at $40^{\circ} \mathrm{C}$ on the unheat-treated stainless steel plate $(\circ)$, and on the metal plates heat-treated for $10 \mathrm{~min}$ at $150(\bullet), 170(\square)$, $190(\square)$ and $210(\triangle)^{\circ} \mathrm{C}$ sliding speed and temperature dependences as seen from Figs. 5(a) [5]. EG has been reported to form a three-dimensional network structure by the intramolecular interaction between the neighboring EG molecules [16], and then the addition of EG to the undiluted PEG400 in the stainless petri dish might result in the conformational change in the regular structure of the PEG400 film which was formed on the metal oxide surface. Since the change in the orientation of the lubricant molecules on the sliding surface caused the prevention of the movement of a ball on the sliding surface, the friction coefficient might increase with increasing in the EG content of the mixed solution as shown in Figs. 3 and 5(b).

\section{Conclusion}

The friction coefficient of the mixed solution of PEG400 and EG in the stainless petri dish showed the maximum value at EG content 70 mass $\%$ at a sliding speed of $0.05 \mathrm{~m} / \mathrm{s}$, the temperature $40^{\circ} \mathrm{C}$ and $1 \mathrm{~N}$. The friction coefficients of undiluted PEG400 (i. e. EG content 0 mass $\%$ ) and undiluted EG (i. e. EG content $100 \mathrm{mass} \%$ ) were not influenced by the temperatures of the lubricants, but the maximum values of the friction coefficients at EG content 70 mass \% appeared at 20 and $40^{\circ} \mathrm{C}$ at the sliding speeds of 0.1 and $0.05 \mathrm{~m} / \mathrm{s}$, respectively. Because the maximum values of the friction coefficients occurred only in the mixed solutions of PEG400 and EG, the appearance of the maximum friction coefficient is seemed to be caused by the intermolecular interaction between the PEG400 and EG molecules. The contact angle of the mixed solution of PEG400 and EG at $40^{\circ} \mathrm{C}$ increased with an increase in the EG content in the lubricant on the unheat-treated metal plate, but showed the maximum value at EG content 60 mass $\%$ on the metal plate which was heat-treated for $10 \mathrm{~min}$ at $190^{\circ} \mathrm{C}$. The maximum contact angle appeared only on the heat-treated metal plate, and was caused at the same EG content as the maximum friction coefficient at the sliding speed of $0.05 \mathrm{~m} / \mathrm{s}$ appeared. The agreement between the EG content dependences of the friction coefficient and the contact angle might indicate that the maximum values of the friction coefficient and contact angle is due to the intermolecular interaction between PEG400 and EG molecules on the metal oxide surface.

\section{References}

[1] Lemar, R. L., "Factors Affecting Sonic Degradation of Polymer Solutions," Rock Island Arsenal, Rock Island, III., Tech. Rept., 6, 1, 1967, 19-23.

[2] Van Horne, W. L., "Viscosity Loss Effects of Polymeric Viscosity Modifiers," Division of Petroleum Chemistry, American Chemical Society, Preprints 1, 4, 1956, 26-31. 
[3] American Society for Testing Material, Philadelphia, Pa., "Supplementary Preprint to the 1961 Report of Committee D-2 on Petroleum Products and Lubricants," Appendix VII, 1961, 61-66.

[4] Hachiya, K. and Nitta, T., "Relationship between Friction Coefficient, Viscosity and Compressibility of Polyethylene Glycol," Tribology Online, 3, 2008, 70-75.

[5] Hachiya K. and Tanaka T., "Relationship between Friction Coefficient, Contact Angle and Infrared Absorbance of Polypropylene Glycol on Metal Surface", Tribology Online, 8, 2, 2013, 227-233.

[6] Hirano, F., Sakai, T. and Yamamoto, Y., "Effect of Oxide Film Formation on Friction-Temperature Characteristics of Oils, Especially in Four-Ball Testing," Proc. 6 th Leeds-Lyon Symp., 1980, 298-306.

[7] Hachiya, K., Moriyama, Y. and Takeda, K., "Kinetics of Ionic Adsorption-Desorption at Solid-Liquid Interface," in Encyclopedia of Surface and Colloid Science, Taylor \& Francis, New York, 4, 2006, 3219-3232.

[8] Hachiya, K., Moriyama, Y. and Takeda, K., "Ionic Adsorption/Desorption Kinetics," in Interfacial Dynamics, ed. Kallay, N., Surfactant Science Series, Chap. 9, Marcel Dekker, New York, 1999, 351-403.

[9] Hachiya K. and Tanaka T., "Relationship between Contact Angle, Infrared Absorbance, and
Compressibility of Diol Compounds on Metal Surface", Chem. Lett., 41, 10, 2012, 1229-1231.

[10] de Gennes, P. G., "Wetting: Statics and Dynamics," Rev. Mod. Phys., 57, 1985, 827-863.

[11] Förch, R., Schönherr, H. and Jenkins, A. T. A., "Surface Design: Applications in Bioscience and Nanotechnology," Wiley-VCH., Weinheim, 2009, 471.

[12] Stuehr, J., "Ultrasonic Methods, Techniques of Chemistry," Vol. 6, Part 2, ed. Hammes, G. G., Wiley-Interscience, 1973, 237.

[13] McClements, D. J. and Powey, M. J. W., "Ultrasonic Solid Fat Content Determination," Ultrasonic International Conf. Proc., Butterworths, London, 1987, 43-47.

[14] McClements, D. J., Dickinson, E., Dungan, S. R., Kinsella, J. E., Ma, J. G. and Powey, M. J. W., "Effect of Emulsifier Type on the Crystallization Kinetics of Oil-in-Water Emulsions Containing a Mixture of Solid and Liquid Droplets," J. Colloid Interface Sci., 160, 1993, 293-297.

[15] Tanford, C., "Physical Chemistry of Macromolecules," John Wiley \& Sons, 1961, 390.

[16] Ottania, S., Francesconib, R., Comellia, F. and Castellarib, C., "Excess Molar Enthalpies of Binary Mixtures Containing Poly (Ethylene Glycol) $200+$ Four Cyclic Ethers at (288.15, 298.15 and 313.15) $\mathrm{K}$ and at Atmospheric Pressure," Thermohimica Acta, 401, 2003, 87-93. 